\title{
Lifetime Estimation of IGBT Power Modules for Reliability Study of Wind Turbine Systems
}

DOI:

10.1049/icp.2021.1111

\section{Document Version}

Accepted author manuscript

Link to publication record in Manchester Research Explorer

\section{Citation for published version (APA):}

Ahmedi, A., Barnes, M., Levi, V., Carmona Sanchez, J., Madariaga, A., Ng, C., \& Jia, C. (2021). Lifetime

Estimation of IGBT Power Modules for Reliability Study of Wind Turbine Systems. 729 - 734. Paper presented at The 10th International Conference on Power Electronics, Machines and Drives.

https://doi.org/10.1049/icp.2021.1111

\section{Citing this paper}

Please note that where the full-text provided on Manchester Research Explorer is the Author Accepted Manuscript or Proof version this may differ from the final Published version. If citing, it is advised that you check and use the publisher's definitive version.

\section{General rights}

Copyright and moral rights for the publications made accessible in the Research Explorer are retained by the authors and/or other copyright owners and it is a condition of accessing publications that users recognise and abide by the legal requirements associated with these rights.

\section{Takedown policy}

If you believe that this document breaches copyright please refer to the University of Manchester's Takedown Procedures [http://man.ac.uk/04Y6Bo] or contact uml.scholarlycommunications@manchester.ac.uk providing relevant details, so we can investigate your claim.

\section{OPEN ACCESS}




\title{
LIFETIME ESTIMATION OF IGBT POWER MODULES FOR RELIABILITY STUDY OF WIND TURBINE SYSTEMS

\author{
Arsim Ahmedi ${ }^{*}$, Mike Barnes ${ }^{1}$, Victor Levi ${ }^{1}$, Jesus Carmona-Sanchez, \\ Ander Madariaga ${ }^{2}$, Chong $\mathrm{Ng}^{2}$, Chunjiang Jia ${ }^{2}$
}

\author{
${ }^{1}$ Department of Electrical \& Electronic Engineering, The University of Manchester, M13 9PL, Manchester, UK \\ ${ }^{2}$ Offshore Renewable Energy (ORE) Catapult, G1 1RD, Glasgow, UK \\ *email: arsim.ahmedi@manchester.ac.uk
}

Keywords: POWER ELECTRONICS, IGBT, THERMAL MODELLING, LIFETIME ESTIMATION, OFFSHORE WIND TURBINES

\begin{abstract}
In this paper, a method for lifetime estimation of insulated-gate bipolar transistor (IGBT) power electronics (PE) modules in offshore wind turbine (WT) applications is presented. The PE module is studied using a time-series WT simulation model. The WT model employs a detailed representation of the system, including a two-mass representation of the mechanical side, $\mathrm{d}-\mathrm{q}$ representation of the permanent magnet synchronous generator (PMSG), and an appropriately controlled back-to-back voltagesource converter (BVSC). Additionally, in order to monitor the temperature cycling, a thermal model which considers the losses in an IGBT module has been added. The temperature cycles are counted using a rain flow algorithm and the resulting effect on lifetime is calculated using Miner's rule for damage accumulation. The system is parametrised according to current state-of-theart offshore wind turbine technology.
\end{abstract}

\section{Introduction}

Power generation from offshore wind energy is a rapidly emerging technology. As wind increases its share in the overall generation, its reliability becomes more important for reasons such as power system stability and cost-effect of failures [1]. Additionally, reliability is an important driver of the Levelized Cost of Electricity (LCoE) for power generation assets [2], [3].

From various failure studies [4]-[8], it has been concluded that one of the most frequently failing assemblies of a WT system is the electrical system. A crucial sub-assembly in this category is the power converter. The high rate of occurrence of failures is a bigger issue for WTs comprising offshore wind farms where the access for intervention is more expensive and difficult, thus increasing the resulting downtime [2].

The study of reliability and failure mechanisms of PE systems is a complicated multidisciplinary task [9]. Work concerning the failure and lifetime estimation of $\mathrm{PE}$ in different applications has been previously done and various models have been created [9]-[13]. This previous work has identified temperature cycling in the device structure as one of the most critical failure causes in PE systems. The temperature cycling is directly related to the loading profile of the PE device - so when the lifetime is assessed, the applied load mission profile has to be considered. The load in the case of WTs is irregular and proportional with the wind profile, which in itself has an unpredictable nature.

There are several publications that have considered the importance of mission profile when studying the reliability of the PE. In [10], a procedure of extracting thermal cycles and using them to predict lifetime for PE in hybrid vehicles is developed. The approach in that paper builds up on the previous traditional approaches such as Coffin-Manson approach [11] and standard rain flow counting algorithms. In [12], a similar analysis has been done and a comparison between two PE choices for a WT application was made. The difference of results in terms of lifetime prediction between the two choices was fairly significant - this confirmed the importance of being able to study PE reliability starting from the design phase of the system. Other papers [13], [14] have considered and developed more detailed models for PE failure and lifetime prediction, analysing the physical creep and stress strain behaviour. The extensive work that has been done on the physical and analytical modelling of the PE device failures has also been implemented for WT applications. However, the mission profile dependence in the WT case is more complicated because of the stochastic and highly varying wind input. Consequently, mission profile and loading deserves more attention for PE applied in WTs. This has been considered in more detail in [12], [15], [16]. In [17] the authors have proposed an approach that considers wind mission profile with three different 'focus' levels in order to count thermal cycling in a yearly timespan. This kind of approach was considered necessary because the thermal cycling depends on several factors and can change in cycles smaller than a second but also in cycles with much lower frequency as a consequence of the change in the average wind speed or the ambient temperature throughout different periods in a year. As a result, it is important to identify certain aspects of the modelling which affect the result of the simulated phenomenon - in this case lifetime estimation.

This paper presents a model used to investigate the effect of high-resolution wind data input in the estimation of the lifetime consumption for IGBT power modules. The paper is organised so that section 2 presents the backgroud theory and equations used to build the model; in section 3 the model is used to analyse two different case studies; and section 4 gives the conclusions drawn from the case studies with suggestions on how the methodology and approach can be improved. 


\section{Methodology}

\subsection{Failure mechanisms}

The most common cause of failures in typical IGBT based power modules is the difference in Coefficients of Thermal Expansion (CTEs) between different layers of the module. Because of the temperature cycling and the different CTEs, after a certain number of cycles, cracks propagate in the interface between different layers and the (electrical/thermal) contact is compromised. This leads to a failure. Most common thermo-mechanical failure modes include bond wire lift-off, crack in the chip-copper solder, crack in the copper-substrate solder as well as crack propagation within the ceramic substrate [9]. The failure mode depends on several factors: magnitude of temperature cycles, average temperature, frequency of temperature cycles, material properties, etc. These parameters can be used to develop analytical models for accurately predicting the dominant failure modes and estimated lifetime of the module.

\subsection{Physics of Failure}

Physics of Failure (PoF) and the strength-stress approach is a developing methodology in reliability of PE systems [18]. Because of reasons such as statistical uncertainty, required multidisciplinary approach and lack of reliability information for the wider audience, its utilisation in power electronics reliability research is still ongoing.

The strength of a population of PE modules is usually assessed in laboratory testing conditions by manufacturers. The statistical distribution of results is given in datasheets with the so-called B10 lifetime curves - expected lifetime of the modules as a function of temperature cycling range. These curves can be used as a starting point in order to build simulations and analytical methods - when doing the testing from scratch is not feasible.

The load (stress) for the chosen PE module of a WT depends on the wind profile and the electro-mechanical behaviour of the WT system. In this paper, these are simulated using MATLAB/SIMULINK and make up an important part of the proposed strength-stress lifetime model shown in Figure 1.

The layout of the WT system is shown in Figure 2 [19]. The time-series simulation is built using a two-mass drive-train representation for the mechanical side, described with differential equations in (2.1). The WT is adapted from the NREL 5-MW baseline offshore wind turbine [20].

$$
\begin{aligned}
& J_{w} \frac{d \omega_{w}}{d t}=T_{w}-k_{w g} \theta_{w g}-d_{w g} \frac{d \theta_{w g}}{d t} \\
& J_{g} \frac{d \omega_{g m}}{d t}=k_{w g} \theta_{w g}+d_{w g} \frac{d \theta_{w g}}{d t}-T_{g e} \\
& \frac{d \theta_{w g}}{d t}=\omega_{w}-\omega_{g m}
\end{aligned}
$$

For the electrical part, $\mathrm{d}-\mathrm{q}$ representation of the generator stator equations, shown in (2.2), are utilised. These equations are used for implementing the adequate control of the BVSC.

$$
\begin{aligned}
& v_{\mathrm{sd}}=R_{\mathrm{s}} i_{\mathrm{sd}}+L_{\mathrm{sd}} \frac{d i_{\mathrm{sd}}}{d t}-\omega_{\mathrm{r}}^{\mathrm{e}} L_{\mathrm{sq}} i_{\mathrm{sq}} \\
& v_{\mathrm{sq}}=R_{\mathrm{s}} i_{\mathrm{sq}}+L_{\mathrm{sq}} \frac{d i_{\mathrm{sq}}}{d t}+\omega_{\mathrm{r}}^{\mathrm{e}} L_{\mathrm{sd}} i_{\mathrm{sd}}+\omega_{\mathrm{r}}{ }^{\mathrm{e}} \Psi_{m}
\end{aligned}
$$

To control the DC link, a small-signal differential eq. - given in $(2.3)$ - describing the current flow in the capacitor is used. $C_{d c} \frac{d \Delta v_{d c}}{d t}=\Delta i_{d c_{g e n}}-\frac{3}{2} \frac{i_{d_{n 0}}}{v_{d c 0}} \Delta v_{d_{n}}-\frac{3}{2} \frac{v_{d_{n 0}}}{v_{d c 0}} \Delta i_{d_{n}}+\frac{3}{2} \frac{v_{d_{n 0}} i_{d_{n 0}}}{v_{d c 0}^{2}} \Delta v_{d c}$

Symbols in (2.1), (2.2) and (2.3) have their usual meaning.

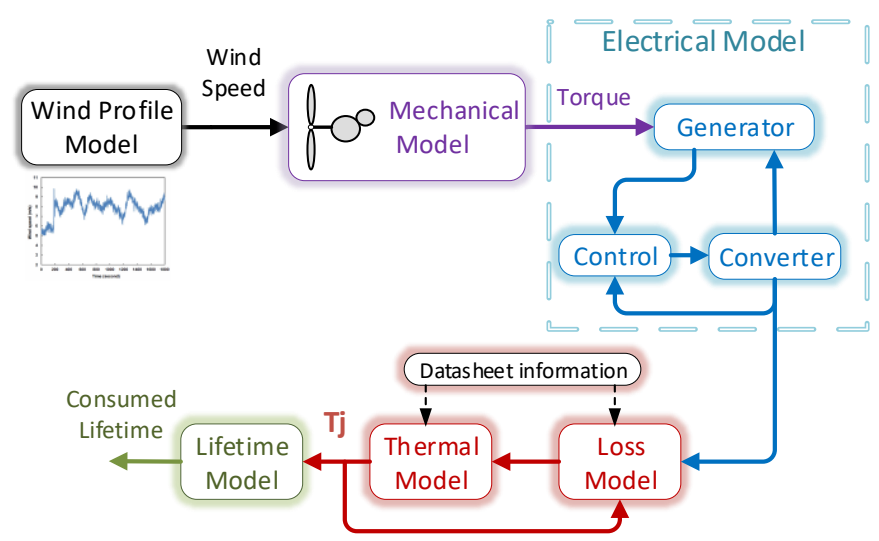

Figure 1 Lifetime model

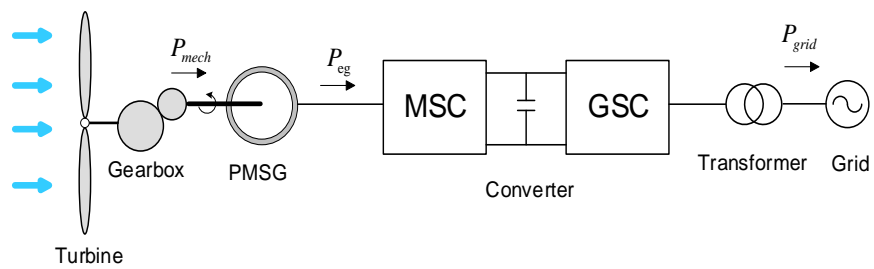

Figure 2 WT system layout

The main stress on a PE module is a consequence of the temperature cycling which is generated from the losses inside the device. Therefore, in the following sections, the used loss and thermal model in the proposed lifetime estimation are given.

\subsection{Losses model}

Conduction losses of the IGBT/Diode are calculated with [21]:

$$
P_{\text {con }}\left(I_{c}, T\right)=\left(k_{0}+k_{1} \cdot T\right) \cdot I_{c}+\left(m_{0}+m_{1} \cdot T\right) \cdot I_{c}^{2}
$$

Where $I_{c}$ is the current through the chip, and $k_{0}, \mathrm{k}_{1}, \mathrm{~m}_{0}, \mathrm{~m}_{1}$ are coefficients used to implement temperature-dependent calculation of losses using curve fitting of datasheet information.

Switching/reverse recovery losses are [22]:

$$
\begin{aligned}
& E_{o n+o f f}=E_{o n+o f f}^{r e f} \cdot\left(\frac{V_{c c}}{V_{c c}^{r e f}}\right)^{K_{v 1}} \cdot\left(1+K_{T, s w} \cdot\left(T_{j}-T_{j}^{r e f}\right)\right) \\
& E_{r r}=E_{r r}^{r e f} \cdot\left(\frac{V_{c c}}{V_{R}^{r e f}}\right)^{K_{v 2}} \cdot\left(1+K_{T, r r} \cdot\left(T_{j}-T_{j}^{r e f}\right)\right)
\end{aligned}
$$


Where with ref are indexed the reference values for the datasheet information, which using $K_{v 1}, K_{v 2}$ are scaled to the operating voltage. With the constants $K_{T, s w}$ and $K_{T, r r}$ the temperature dependence of the switching losses is added.

\subsection{Thermal model}

Manufacturer datasheets usually give a Foster network thermal impedance from junction to case. This representation does not give any information on the temperature distribution across the layers and the thermal resistances and capacitances do not have a physical meaning. For building the thermal network of the overall system it is necessary to perform a Foster to Cauer transformation [22]. The transformation has been done using the methodology derived in [23] utilising the impedance equations in the Laplace domain.

Using the Foster to Cauer transformation and adding the thermal impedances of the heatsink and the case-heatsink connection, the complete Cauer network of the IGBT module with a single Diode and IGBT is built. The built thermal and loss models were compared with the manufacturer's online simulation tool and they were verified to give acceptable and comparable results.

The goal of the previously described loss and thermal models, is to be able to observe the temperature cycling behaviour of the IGBT module when choosing the system's operating conditions.

\subsubsection{Lifetime estimation model}

The simplest model to represent the wear out effect as a function of temperature cycling is the Coffin-Manson model as given in eq. (2.6). This model was originally developed to represent fatigue in materials [15]. It is also implemented in the process of producing the lifetime curves by manufacturers. It describes the relationship of the expected number of 'cycles to failure' and the temperature cycling range:

$$
N_{f}=a \cdot \Delta T^{-n}
$$

Where $N_{f}$ is the number of cycles to failure for the corresponding $\Delta T$, which represents the temperature cycling range, and $\mathrm{a}$ and $\mathrm{n}$ are the Coffin-Manson relationship parameters known as the scale parameter and the shape parameter respectively.

If experiments are made, the parameters $a$ and $n$ in (2.6) are calculated from experimental data, which is how this model was originally implemented. Alternatively and for the work in this paper, datasheet information is treated as experimental data: a power law is fitted to the $N_{f}$ values at different ranges $\Delta T$ that are given in the datasheet with the $\mathrm{B}_{10}$ curve. This enables extrapolation of the power law over the whole temperature range. This approximation introduces a certain inaccuracy especially for low temperature ranges. Additionally, inverse power law (2.6) considers solely the temperature range dependence. Other parameters and improved Coffin-Manson models have to be considered, such as Coffin-Manson-Arrhenius, Norris-Landzberg and Bayerer models [15].
By counting the thermal cycles of the module for certain operating conditions and having the number of cycles to failure defined by (2.6), the cosnumed lifetime of the module in those conditions can be estimated. This is done using the PilgrimMiner rule for damage accumulation:

$$
D=\sum_{i} \frac{n_{i}}{N_{f, i}}
$$

Where $n_{i}$ is the number of cycles which are counted at a certain temperature range, and $N_{f, i}$ is the expected number of 'cycles to failure' (from eq. (2.6) or improved models) that the device is expected to last for the same range. The sum of this ratio for all cycles gives the total damage (2.7). When total damage i.e. (lifetime consumption) is equal to 1 , the product is expected to have failed - the probability of failure is $10 \%$ given that a $B_{10}$ curve is used.

The counting of the cycles was done using a standard rain flow algorithm where cycles and half cycles between temperature reversals are counted according to ASTM E1049 standard [24].

\section{Lifetime estimation studies}

\subsection{Constant wind input}

Initially, in this section, the methodology introduced above is implemented assuming steady state operation of the WT model with a constant wind speed input. In Figure 3, an 80 millisecond interval with a steady state operation and constant wind input of $11.4 \mathrm{~m} / \mathrm{s}$ is presented. This figure shows the losses in the IGBT and diode chips as well as the resulting junction temperature cycling.

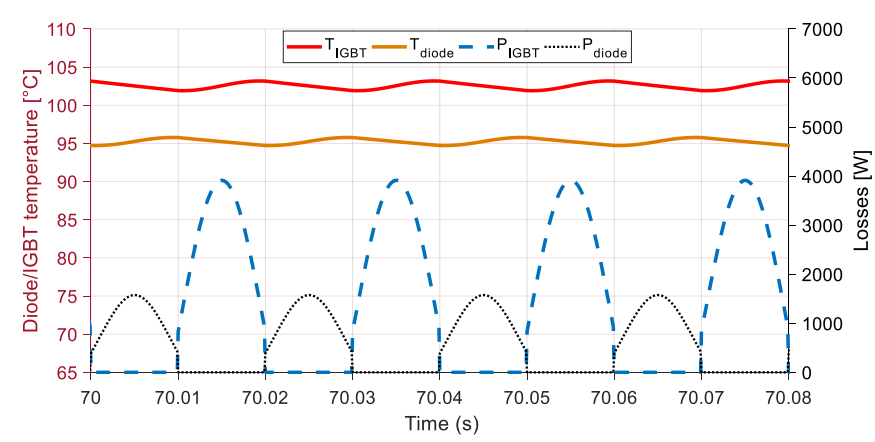

Figure $350 \mathrm{~Hz}$ temperature cycling of an IGBT module as part of a switch-averaged model of VSC

If the temperature cycles in Figure 3 are counted, the ratio given in (2.7) can be implemented and the percentage of the consumed lifetime calculated. This has been done for different steady state speeds for a 10 minute period and the calculated results are shown in Figure 4. The simulated points are shown with blue diamonds, while the red curve represents the fitted trend between the simulated points. The consumed lifetime percentage rises proportionally with the power flow through the converter. This type of calculation will show constant lifetime wear for speeds above rated, where the pitch control limits the power extracted from the wind turbine. However in the case of a realistic turbulent wind speed, more transients some faster than the pitch control response - are present and 
hence additional temperature cycles. The magnitude of those cycles can be quite high and significant.

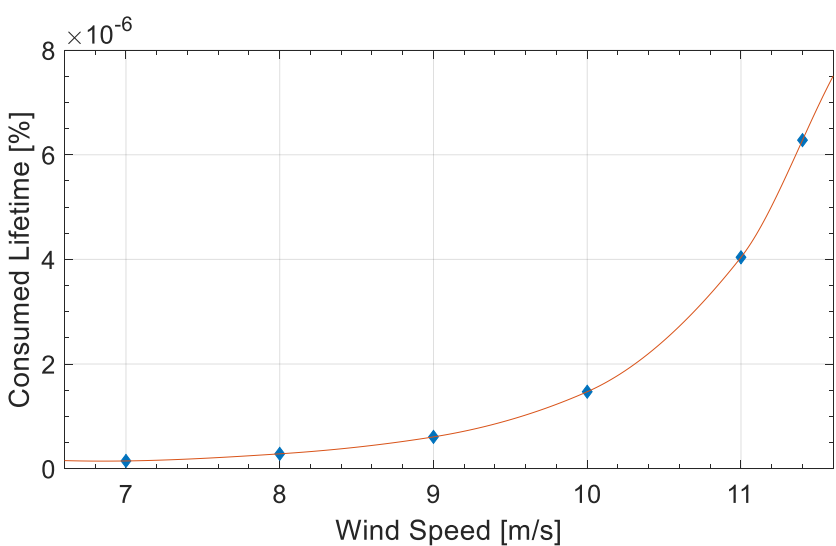

Figure 4 IGBT consumed lifetime against constant wind speed for a steady state operation in a 10 minute interval

\subsection{Turbulent wind speed}

The analysis and WT model that was described in the previous sections was run with an input containing 10 minutes of turbulent wind data with $0.05 \mathrm{~s}$ resolution. The wind data, shown in Figure 5, was produced using TurbSim, a toolbox provided by NREL. Initially, it was synthetised for average speed of $18 \mathrm{~m} / \mathrm{s}$ and then the same turbulence was rescaled and used for lower average speeds for different studies - in Figure 5 the 10 -minute average is $10.4 \mathrm{~m} / \mathrm{s}$. Pitch control is not activated.

After running the simulation model, a number of results can be extracted and analysed as sequential steps towards the final goal of quantifying the lifetime wear of the PE module. The study is done on an ABB IGBT module of HiPak family. Initially, based on the analytical loss model introduced in the previous section, the turbulent wind speed input corresponds to generated losses in the diode and IGBT chips of the module as shown in Figure 6. As a result of these losses, there is a temperature change inside both chips of the module. This change is represented by the junction temperatures of both the diode and IGBT chips - this is shown in Figure 7. Note that the analysis starts after the 100 second mark - time allowed for the initial transients to be finished.

Because of the higher generated losses - dominated by the switching losses - the IGBT chip temperature is higher than the diode junction temperature. Both chips have the same effect when it comes to reliability as a consequence of temperature cycling. However, because the same failure modes are considered, the analysis comes down to the IGBT chip temperature cycling - as this would likely trigger a failure first given that the temperature is higher. Obviously this is not true for failure causes other than thermal cycling.

In order to implement the Miner's rule as in (2.7), temperature cycle counting has to be done. To do this, a MATLAB function implementing a rain flow algorithm is used. The load (temperature) cycling history is observed as a sequence of load reversals.

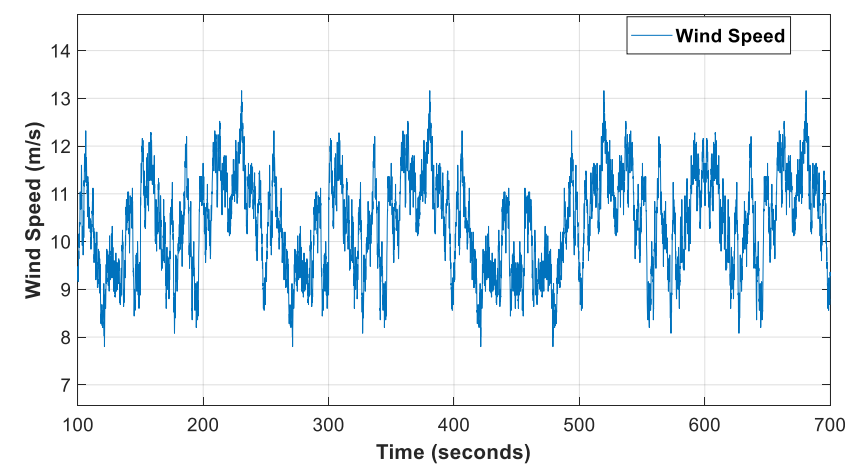

Figure 5 Turbulent wind speed profile with average $10.4 \mathrm{~m} / \mathrm{s}$

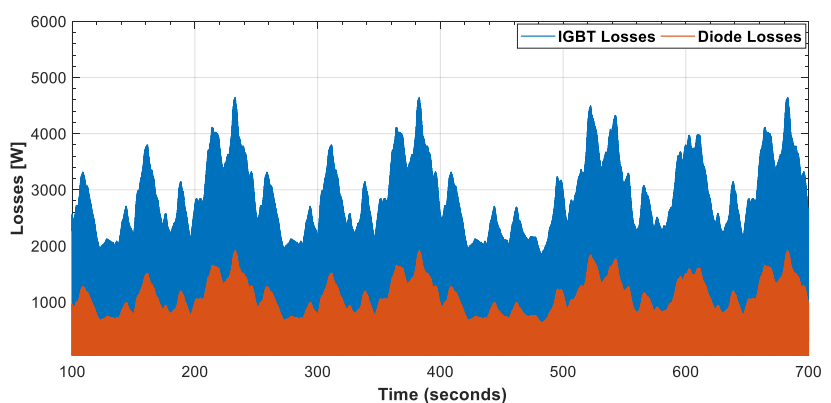

Figure 6 IGBT and Diode instantaneous losses for turbulent wind input

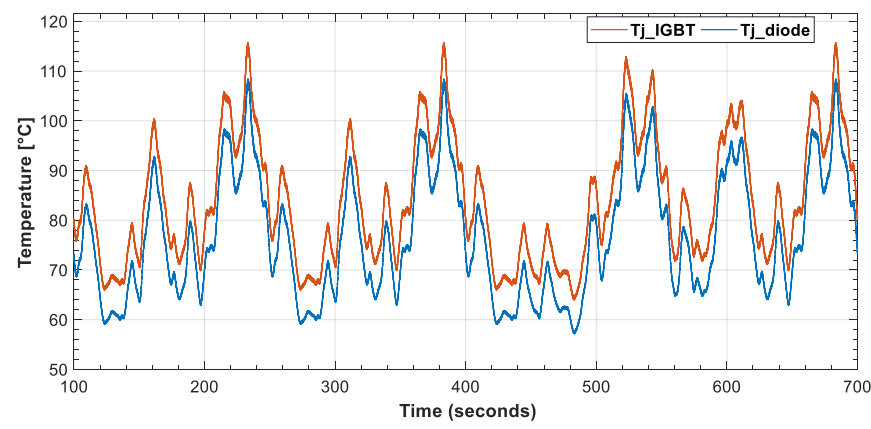

Figure 7 IGBT and Diode junction temperature for turbulent wind input

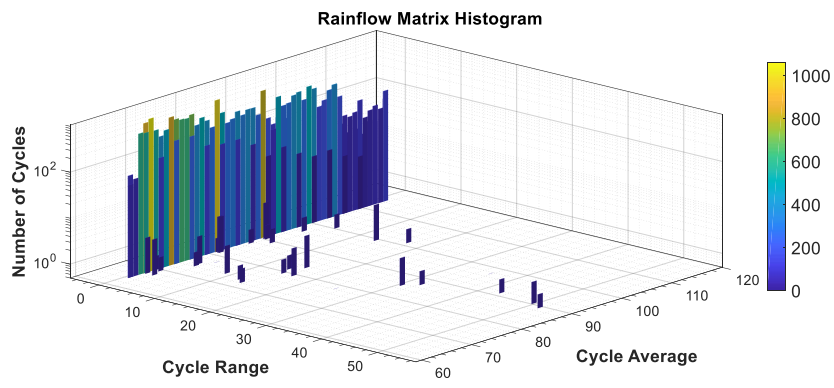

Figure 8: Rain flow matrix histogram for IGBT temperature cycling

For the 10-minute IGBT junction temperature change shown in Figure 7, the visual distribution of the counted cycles at different cycle ranges and average temperatures is shown in Figure 8. A logarithmic scale is used for the Z-axis (Number of Cycles axis) so that the fewer cycles at higher temperature ranges can be visible. The highest number of counted cycles is at a small range $\left(0\right.$ to $\left.2{ }^{\circ} \mathrm{C}\right)$. A better view of the number of cycles as a function of temperature range without considering the average temperature is given in Figure 9. The cycles have 
been distributed in highly narrow histogram bins in order to show the presence of different cycles.

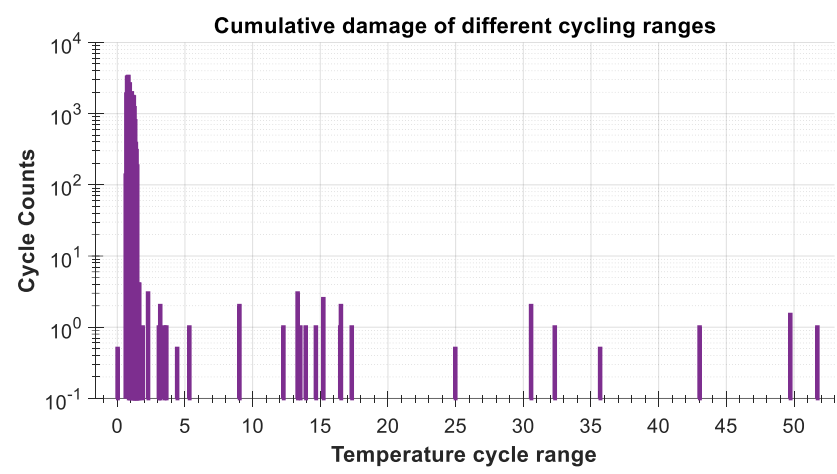

Figure 9 Cycle count histogram as a function of temperature range

Up to this level, the accuracy of the model is compromised by its approximations, including: analytical models for switching and conduction losses, WT AFWT model [19], wind speed uncertainty (e.g. wake effect, variation within site), converter model uncertainty (e.g. switch-averaged model). For most common analysis and for the one intended in this paper, the errors introduced by these approximations can be neglected.

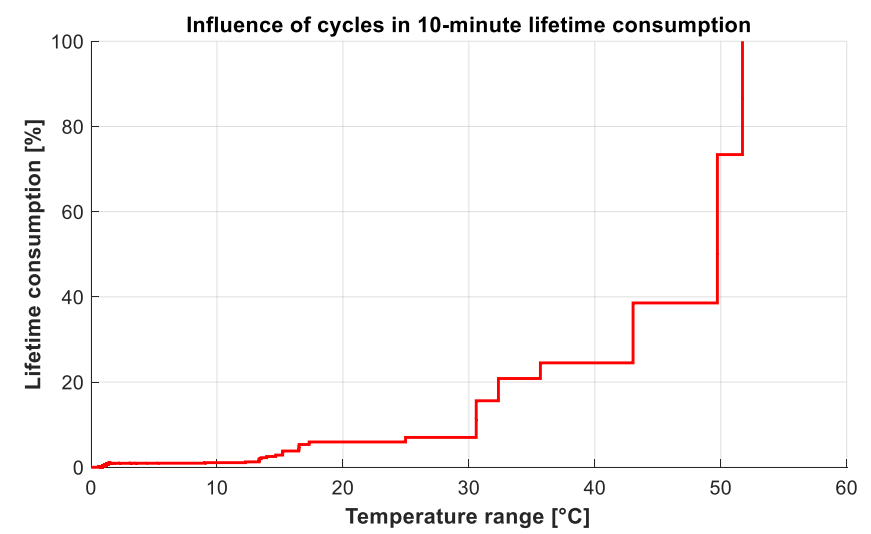

Figure 10 Cumulative influence of cycles with different range in the total lifetime consumption for a period of 10 minutes.

Bond wire lift-off failure mode

Next, in order to quantify lifetime consumption, the datasheet information on load-cycling capability of the module has to be entered. The most straightforward way to do this is to approximate a power law - the Coffin-Manson model - to the $\mathrm{B}_{10}$ curve (see section 2.4.1). This method adds inaccuracy because of the fitting limitations with a power law but also because of the more scarce information for small temperature ranges of less than $10{ }^{\circ} \mathrm{C}$. Additionally, this method does not account for the average temperature of cycles. If a calculation of lifetime using this method is done for the considered case study, the results, when it comes to influencing lifetime consumption, unsurprisingly hint on a clear dominance of the bigger cycles over smaller ones even though the latter are by far more frequent. The influence of all the cycles as a function of temperature range is given with the cumulative lifetime distribution curve in Figure 10.

The consumed lifetime is calculated to be $0.0002984 \%$ or $298.4 \cdot 10^{-6} \%$ in the studied 10 minute interval. This is by far higher than the highest for constant speed in Figure 4 $6.28 \cdot 10^{-6} \%$ for wind speed of $11.4 \mathrm{~m} / \mathrm{s}$. If it is assumed that the exact same turbulent wind profile is repeated for the course of one year, the result can be scaled to a yearly lifetime consumption of $15.6 \%$. This is high but it is likely to be an overestimation: the estimation error because of the high sensitivity of the lifetime calculation on several exact parameters is amplified when yearly extrapolation is made; and realistically it is certain that at some periods in a year the wind will be less turbulent.

\section{Conclusion}

This paper reviewed a modelling technique for lifetime estimation of IGBT switching devices in WT applications. A full layout of the methodology from wind speed input to lifetime quantification is presented.

It is a common practice in industry for wind data to be stored in SCADA systems as 10 minute averaged values. This paper presents analysis on the difference that approximation makes when PE reliability is evaluated. Initially, using different constant (averaged) wind speeds, the lifetime consumption of the IGBT for 10 minute operation was calculated. The temperature cycles in this case were with a high frequency but a small range - consequence of the instantaneous power flow in the IGBT switch.

Next, the model was run using 10 minutes of turbulent wind data as an input. Using this setup, the extracted results at each step of the methodology were presented. The lifetime consumption was significantly higher than in the case of constant i.e. averaged wind speed. The main conclusion here is that the transients inside a 10 minute window can have a substantial impact and the lifetime consumption can be greatly underestimated when these transients are disregarded. Initial results show that cycles with larger temperature change have the highest contribution to lifetime consumption.

This paper addresses the failure mode of bond-wire lift off, as it is expected that every junction temperature change is reflected at that location instantaneously. On the other end, for other layers, e.g. at the baseplate, some high frequency temperature excursions might not be seen at all. This inherent filtering is a consequence of the thermal capacitance, while the thermal resistance induces a difference in average temperature between different layers. Thus, one other aspect that needs to be included in further studies is failure modes and temperature propagation in other layers of the module package.

The methodology applied in this paper can be improved. In order to verify and validate it and the made conclusions, further work needs to be undertaken. The lifetime with pitch control above rated speed should be further analysed. Other models except the simple Coffin-Manson considering more parameters can be added. More data about the operating conditions of the WT as well as the reliability data for the PE converter can be used to improve the analysis. When the appropriate number of comparisons between models of different fidelity will have been made, the model which will give the required accuracy while being as simple and computationally efficient as possible can be built. 


\section{Acknowledgement}

The work in this paper was carried out with the support of the Offshore Renewable Energy Catapult (OREC) as part of the Electrical Infrastructure Research Hub (EIRH).

\section{References}

[1] F. Blaabjerg, M. Liserre, and K. Ma, "Power Electronics Converters for Wind Turbine Systems," IEEE Trans. Ind. Appl., vol. 48, no. 2, pp. 708-719, Mar. 2012.

[2] M. Barnes, K. Brown, J.Carmona, et al, "Technology Drivers in Windfarm Asset Management,", HOME Offshore project position paper, DOI: 10.17861/20180718, Jun. 2018.

[3] P. Tavner, "Wind turbine systems," in Reliability of Power Electronic Converter Systems, H. S. Chung, H. Wang, F. Blaabjerg, et al, Eds. The Institution of Engineering and Technology, 2015, pp. 165-194.

[4] M. Wilkinson, K. Harman, B. Hendriks, et al "Measuring Wind Turbine Reliability - Results of the Reliawind Project," 2011.

[5] M. Wilkinson, B. Hendriks, F. Spinato, et al, "Methodology and Results of the Reliawind Reliability Field Study," in European Energy Conference, EWEC 2010.

[6] S. Faulstich, "Deliverable WP7 3.3, Component reliability ranking with respect to WT concept and external environmental conditions," 2010.

[7] B. Hahn, M. Durstewitz, and K. Rohrig, "Reliability of wind turbines: Experiences of 15 years with 1,500 WTs," Wind Energy Proc. Euromech Colloq, 2006.

[8] S. Pfaffel, S. Faulstich, and K. Rohrig, "Performance and reliability of wind turbines: A review," Energies, vol. 10, no. 11, 2017.

[9] H. S. Chung, H. Wang, F. Blaabjerg, et al, Reliability of Power Electronic Converter Systems - The IET. The Institution of Engineering and Technology, 2015.

[10] M. Ciappa, F. Carbognani, P. Cova, et al, "Lifetime prediction and design of reliability tests for highpower devices in automotive applications," IEEE Int. Reliab. Phys. Symp. Proc., vol. 2003-January, no. 4, pp. 523-528, 2003.

[11] S. S. Manson, Thermal stress and low-cycle fatigue. New York: McGraw-Hill, 1966.

[12] H. Wang, K. Ma, and F. Blaabjerg, "Design for reliability of power electronic systems," in IECON 2012 - 38th Annual Conference on IEEE Industrial Electronics Society, 2012, pp. 33-44.

[13] U. Drofenik, I. Kovacevic, R. Schmidt, et al, "Multidomain simulation of transient junction temperatures and resulting stress-strain behavior of power switches for long-term mission profiles," in 2008 11th Workshop on Control and Modeling for Power
Electronics, 2008, pp. 1-7.

[14] I. F. Kovačević, U. Drofenik, and J. W. Kolar, "New physical model for lifetime estimation of power modules," 2010 Int. Power Electron. Conf. - ECCE Asia -, IPEC 2010, pp. 2106-2114, 2010.

[15] C. Busca, R. Teodorescu, F. Blaabjerg, et al, “An overview of the reliability prediction related aspects of high power IGBTs in wind power applications," Microelectron. Reliab., vol. 51, no. 9-11, pp. 1903 1907, 2011.

[16] D. Zhou, F. Blaabjerg, T. Franke, et al, "Comparison of Wind Power Converter Reliability with Low-Speed and Medium-Speed Permanent-Magnet Synchronous Generators," IEEE Trans. Ind. Electron., vol. 62, no. 10, pp. 6575-6584, 2015.

[17] K. Ma, M. Liserre, F. Blaabjerg, et al, "Thermal loading and lifetime estimation for power device considering mission profiles in wind power converter," IEEE Trans. Power Electron., vol. 30, no. 2, pp. 590-602, 2015.

[18] H. Wang, M. Liserre, F. Blaabjerg, et al, "Transitioning to Physics-of-Failure as a Reliability Driver in Power Electronics," IEEE J. Emerg. Sel. Top. Power Electron., vol. 2, no. 1, pp. 97-114, Mar. 2014.

[19] J. Carmona-Sanchez, Z. Lin, M. Collu, et al, “An analysis of the impact of an advanced aero-hydroservo-elastic model of dynamics on the generatorconverter dynamics, for an offshore fixed 5MW PMSG wind turbine," in 15th IET International Conference on AC and DC Power Transmission (ACDC 2019), 2019.

[20] J. Jonkman, S. Butterfield, W. Musial, et al "Definition of a 5-MW Reference Wind Turbine for Offshore System Development," NREL Technical Report, 2009.

[21] J. W. Kolar and U. Drofenik, "A General Scheme for Calculating Switching and Conduction Losses of Power Semiconductors in Numerical Circuit Simulations of Power Electronic Systems," Int. Power Electron. Conf., 2005.

[22] A. Wintrich, N. Ulrich, T. Werner, et al, "Application Manual Power Semiconductors," 2015.

[23] Y. C. Gerstenmaier, W. Kiffe, and G. Wachutka, "Combination of thermal subsystems modeled by rapid circuit transformation," in 2007 13th International Workshop on Thermal Investigation of ICs and Systems (THERMINIC), 2007, pp. 115-120.

[24] ASTM E1049, "Standard practices for cycle counting in fatigue analysis," ASTM Stand., vol. 85, no. Reapproved 2017, pp. 1-10, 2017.

[25] N. Kaminski, "Load-Cycle Capability of HiPaks (TM) 5SYA 2043-01,” ABB Appl. note, pp. 1-8, 2004. 